\title{
Combined Heat and Power Design Considerations for the APR1400
}

\author{
Michał Wierzchowski and Robert M. Field \\ KEPCO International Nuclear Graduate School (KINGS), 658-91 Haemaji-ro, Seosaeng-myeon, Ulju-gun, Ulsan 689-882, Republic \\ of Korea
}

Received: November 07, 2016 / Accepted: November 16, 2016 / Published: March 31, 2017.

\begin{abstract}
To date, nuclear cogeneration applications have been limited, primarily to district heating in Eastern Europe and heavy water production in Canada. With the current global price for oil and energy, this technology is not economically viable for most countries. However, oil and fossil fuel prices are known to be highly volatile, and the Paris Agreement calls for a reduction in fossil fuel use. Under these circumstances, heat supplied by nuclear power may abruptly return to favor. To prepare for such a scenario, this study will investigate design considerations for a prototypical modern nuclear power plant, the Korean APR1400 (advanced power reactor 1400) (e.g., Shin Kori Units 3, 4, Shin Hanul 1, 2, Barakah Units 1, 2, 3, 4). Nuclear cogeneration can impact balance of plant system and component design for the condensate, feedwater, extraction steam, and heater drain systems. The APR1400 turbine cycle will be reviewed for a parametric range of pressures and flow rates of the steam exported for cogeneration to identify major design challenges.
\end{abstract}

Key words: Cogeneration, energy, heat, nuclear energy, steam turbine, design, pressurized water reactor, APR1400.

\section{Introduction}

CHP (combined heat and power) is the use of a heat source to simultaneously supply steam for electricity production in a steam turbine and heat for customer use either onsite or offsite a power plant. Historically, cogeneration has supplied steam for various uses including district heating, process heat (e.g., refineries, industries, food processing), desalination, heavy water production, and hydrogen production (for high temperature steam).

CHP production has developed during the 20th century as an eco-friendly, profitable, and reliable technology [1]. Concurrent generation of two energy carriers was historically based on steam turbine systems of coal fired power plants. Nuclear cogeneration solutions have received attention from researchers in the (former) Soviet Union in order to

Corresponding author: Michał Wierzchowski, M.Sc., research fields: steam turbines, steams cycles, cogen. improve utilization of nuclear fuel. According to Losev et al. [2], four different approaches were taken into consideration:

(1) The use of unregulated steam extraction from the turbine;

(2) The design of mixed, district heating and condensing NPPs (nuclear power plants);

(3) The design of single-purpose NPPs which were to produce only heat utilized in community and domestic heating applications;

(4) The design of specialized NPPs for industrial heating purposes, which could be placed in proximity to the industrial facilities.

From the IAEA (International Atomic Energy Agency) [3], several countries have had past experience with non-electric nuclear applications including: Bulgaria, Canada, the Czech Republic, Hungary, India, Japan, Kazakhstan, Pakistan, Romania, the Russian Federation, Slovakia, Switzerland, and the Ukraine. As of 2007, the Russian Federation had had 
approximately 900 reactor-years of experience with cogen applications. As identified by the IAEA, the largest district heating facility is located in Slovakia with the Bohunice NPP able to supply $240 \mathrm{MWt}$ of heat from two 1,471 MWt units. As for industrial applications, the biggest cogeneration project is located in Ontario, Canada-Bruce A. Originally the four unit CANDU plant could export 5,350 MWt worth of heat equivalent to $\sim 50 \%$ of installed thermal power capacity. This project principally provided heat for heavy water production and other industrial or agricultural users including: (1) a plastic manufacturer, (2) a 30,000 $\mathrm{m}^{2}$ greenhouse, (3) a 12 million liter/year ethanol steam plant, (4) a 200,000 ton/year dehydration, cubing, and pelletizing plant, (5) an apple juice concentration plant, and (6) an agricultural research facility. Today heat export is limited due to a surplus of heavy water with the focus on electricity production.

Due to climate conditions in Northern Europe, cogeneration has become an essential part of the energy mix as district heating is used to distribute the heat from CHP plants for many cities. In pursuit of a carbon-free economy, Finnish energy company FORTUM has investigated the construction of the Loviisa $3 \mathrm{CHP}$, which would export 1,000 MWt worth of heat to Helsinki (located $\sim 70 \mathrm{~km}$ from the NPP site) [4]. Such a solution is projected to reduce $\mathrm{CO}_{2}$ emissions by $6 \%$ and would diminish environmental impacts by reducing heat discharged to the Gulf of Finland.

Large steam export was also planned for the Midland PWR Project in Michigan, USA [5]. The initial design included export steam to the neighboring chemical plant. The project started with construction of two PWR units rated at 2,468 MWt, projected to supply $1,644 \mathrm{t} / \mathrm{h}$ and $193 \mathrm{t} / \mathrm{h}$ of process steam from Unit 1 and 2 , respectively. Such a configuration would have required a specific turbine design for low pressure steam flow path flows in Unit 1, steam export was targeted for $40 \%$ of core output. However, due to cost over-runs and regulatory delays the nuclear portion of the project was never completed and cogen steam is now provided by exhaust heat from simple cycle gas turbines.

\section{Advanced Power Reactor 1400}

\subsection{Overview}

The APR1400 (advanced power reactor 1400) is an evolutionary PWR (pressurized water reactor) developed in the Republic of Korea [6]. The design is based on previous Korean reactor technology, the OPR1000 (optimum power reactor 1000) which has been successfully deployed in South Korea since 1994. The APR1400 is licensed for 3,981 MWt (core). The first APR1400 unit, Shin Kori Unit 3 is currently undergoing startup testing.

\subsection{Secondary System Description}

The steam cycle of APR1400 is comprised of the main $\mathrm{T} / \mathrm{G}$ (turbine-generator) and associated support systems, and the MS (main steam), ES (extraction steam), CD (condensate), FW (feedwater), and HD (heater drain) systems. The turbine-generator system consists of one HPT (high pressure turbine) and three LPTs (low pressure turbines) coupled with the half-speed, 4-pole main generator. Cross-around steam leaving the HPT passes through moisture separator reheaters with two stages of reheat.

The APR1400 CD and FW systems consist of seven points of heating. Extraction lines transport heating steam from the LPTs to the LP FWHs and the deaerator, and from the cross around piping and HPT to the HP FWHs. The arrangement of the steam cycle is illustrated in Fig. 1.

\subsection{APR1400 Coupled with Cogen Steam Export}

Previous analyses [6,7] provided a number of economic and technical advantages of combined power and water generation using APR1400 technology. However, the studies did not address design considerations related to the APR1400 steam cycle. Those issues are addressed here. 


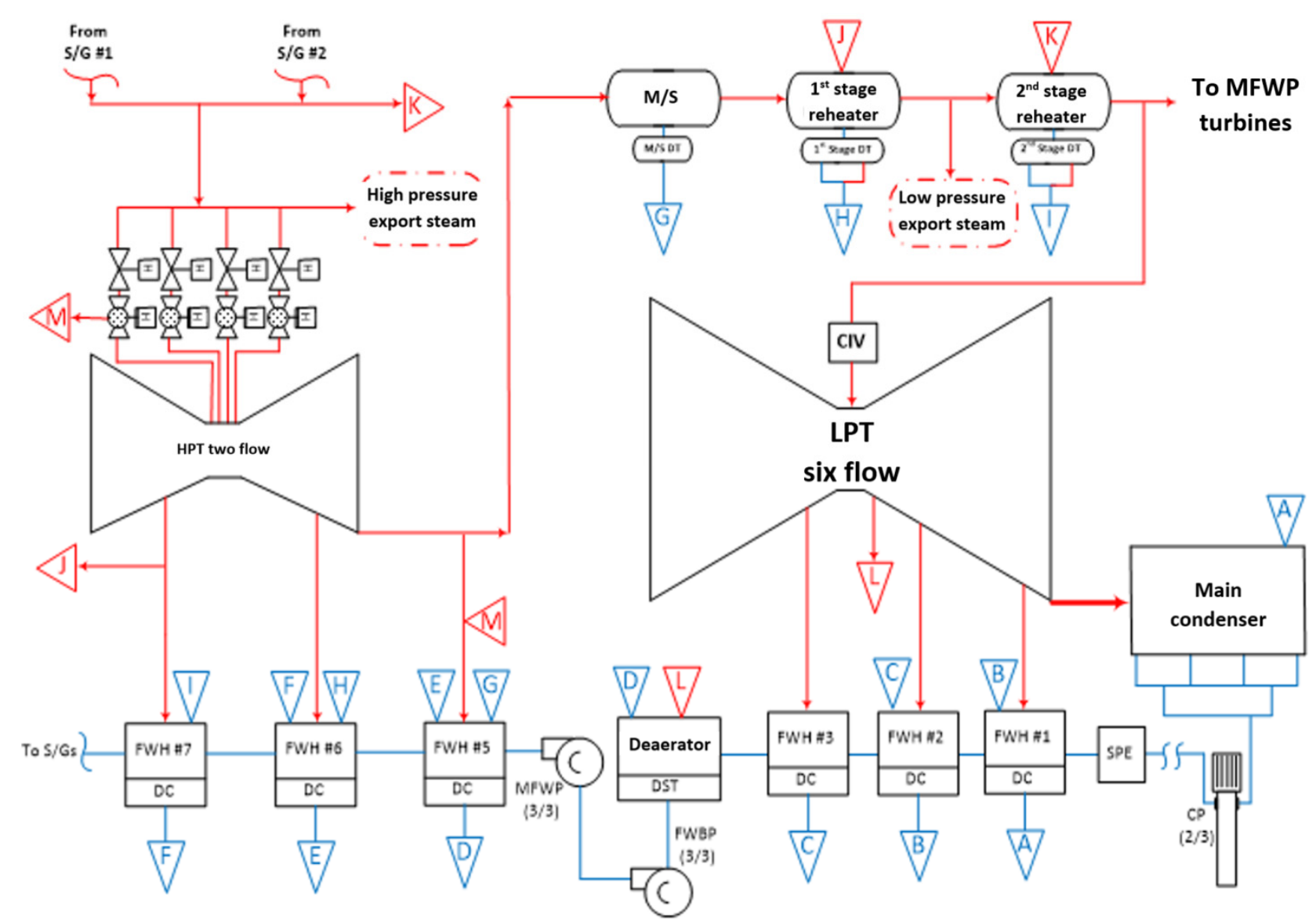

Fig. 1 APR1400 steam cycle—simplified schematic.

\section{Methodology}

\subsection{Export Steam}

Export steam is the steam extracted from the cycle in order to provide steam to an external customer. To ensure the safety of such a design, it is necessary to design a tertiary system which would receive heat from the export steam and generate either hot water or tertiary steam depending on the use. The export steam then condensed in an onsite reboiler should be returned to an injection point in the nuclear steam cycle. Design of the tertiary steam plant does not materially impact design considerations for the nuclear steam cycle and is excluded from the scope of this study.

\subsection{Steam Export Capacity}

The biggest challenge for cogeneration projects is economic viability. This highly depends on electricity market regulations and electric power prices. Economic considerations are not included in this paper. However, in some areas nuclear cogeneration could address the scarcity of clean water or district heating demand. Based on preliminary evaluations, it was assumed that economic forces require that any cogeneration project should have large capacity, equivalent to $\sim 500 \mathrm{MWt}$ or more. Only with large quantities of export steam can the cost of upfront activities (design, licensing, procurement, construction, startup, and preparation for operations) be adequately covered. Theoretically, the risk of such cogen NPP operation is also higher and may have an impact on insurance and public perception of the facility. The maximum capacity of the export steam was assumed as $\sim 1,000 \mathrm{MWt}$. This upper bound is constrained primarily by the technical capabilities of the current 
APR1400 design. As a consequence of these considerations, the analysis was performed for two cases, one with $\sim 500$ and one with $\sim 1,000 \mathrm{MWt}$ of export steam. The analysis for these values was performed using microsoft excel by respecting mass and energy balance in the cycle.

\subsection{Steam Export Location}

There are a number of potential locations in the steam cycle which can be considered for steam extraction. The extraction points selection process is described below.

\subsubsection{High Pressure Turbine Extraction}

The APR1400 double flow HPT is provided with relatively short blades with close spacing. The current design includes three extraction nozzles. To extract large quantities of steam from the HPT steam flow path would require the turbine vendor to redesign the extraction points. Due to the lack of spacing between stages it is likely that large quantities of extraction steam would penalize the HPT steam flow path efficiency.

\subsubsection{Low Pressure Turbine Extraction}

The APR1400 is equipped with three LPT. It is not practical to install the extraction position from these components as follows. First of all, the temperature of the inter-stage low pressure steam is considered too low $\left(\sim 150{ }^{\circ} \mathrm{C}\right)$ for practical purposes. Secondly, the current turbine design involves short blades with close spacing at the first few stages and it would be impossible to efficiently install the extraction nozzles at this point. Additionally, it would be necessary to modify the extraction piping arrangement by changing line sizes, and to introduce additional casing penetrations. To sum up, LPT extraction is considered to be impractical and not feasible.

\subsubsection{MSR (Moisture Separator Reheater) Extraction}

There are two potential positions for MSR extraction of cross-around steam: (1) located downstream of the Moisture Separator (M/S) section, or (2) downstream of the 1st reheat stage bundle. Both locations have a similar saturation temperature of $\sim 185{ }^{\circ} \mathrm{C}$ and this value is suitable for district heating applications. For export of steam from the tertiary side it would be recommended to design the system with extraction downstream of the MSR 1st stage bundle in order to achieve some superheat of the tertiary steam. The location of the MSR extraction was considered as a suitable for either of the cases described above, but the heat balance analysis only includes extraction from the 1st reheat stage bundle Similar heat balance parameters would be expected for the other cross-around extraction location.

\subsubsection{Main Steam Extraction}

Exporting Main Steam from the cycle is not a common practice since it has the highest potential for electricity generation. However, extraction from main steam could be considered for some applications when tertiary steam has to be sent over long distances to a user facility. In such cases, the high pressure for main steam would reduce the tertiary steam line sizes and the electrical generation penalty could be made up by backpressure turbine installation at the customer site.

To conclude, two locations, main steam extraction (HPE (high pressure export)) and MSR (1st stage) Extraction (LPE (low pressure export)) are selected as the focus of this study.

\subsection{Approach}

The base steam cycle is for the APR1400 design for the $60 \mathrm{~Hz}$ market as described in the design control document [7]. However, when operating with large quantities of LPE steam, the cross-around pressure is significantly depressed, and as described below, this results in a large power increase for the HPT and a severe challenge for the MFWP (main feedwater pump) turbines. Therefore, a second case, the "modified" $T / G$ is also examined. For this case, the cross-around pressure for the VWO (valves wide open) condition is raised $\sim 15 \%$. A higher cross-around pressure results in an overall production penalty ( $\sim 7 \mathrm{MWe})$ but mitigates 
several operational challenges for systems and components for both HPE and LPE steam conditions including: (1) impact on the MFWP turbines, (2) line velocities in extraction steam lines, and (3) changes in control valve sizing for normal and emergency drain control valves for the feedwater heaters and MSR drain tanks.

Design conditions were examined for the following systems: (1) MS system, (2) cross-around steam system, (3) ES system, (4) CD system, (5) FW system, and (6) HD system. In addition, components subject to design challenges were reviewed, including: (1) turbine-generator, (2) feedwater heaters, (3) moisture separator reheaters, (4) main condenser, and (5) MFWP (main feedwater pump) turbines.

Steam cycle heat balances were computed for the configuration per Fig. 1 for both the baseline T/G and for the modified $\mathrm{T} / \mathrm{G}$ with an increased cross-around pressure. Twelve cases were considered in all as follows:

- B-APR1400 Baseline T/G

- B-VWO-Valves wide open case

- B-100-100\% reactor power case

- B-H725 - 725 t/h HPE steam baseline case

- B-H1450 - 1,450 t/h HPE steam baseline case

- B-L725 - 725 t/h LPE steam baseline case
- B-L1450 - 1,450 t/h LPE steam baseline case

- M-APR1400 Modified T/G

- M-VWO_Valves wide open case

- M-100-100\% reactor power case

- M-H725 - 725 t/h HPE steam modified case

- M-H1450 - 1,450 t/h HPE steam modified case

- M-L725 - 725 t/h LPE steam modified case

- M-L1450 - 1,450 t/h LPE steam modified case

The thermodynamic parameters were calculated for each case and then used in further analysis of key steam cycle systems and components. As indicated below, large quantities of export steam present certain challenges for the design of systems and components. In particular, the following parameters experience significant adverse changes which may require re-design: (1) HPT shaft power, (2) steam velocities in ES lines, and (3) HD drain control valve capacity.

\section{Results}

Table 1 presents the shaft power and electricity generation without and with cogeneration for all analyzed cases. The table also presents the electricity generation and heat export in each operational case. For the cases with high pressure export, the shaft power is reduced, but it does not have any impact on the proper operation of the turbine. For the case of LPE,

Table 1 Shaft power and net electricity generation analysis.

\begin{tabular}{|c|c|c|c|c|c|}
\hline Units & $\begin{array}{l}\text { High pressure } \\
\text { turbine } \\
(\mathrm{MWs})\end{array}$ & $\begin{array}{l}\text { Low pressure } \\
\text { turbines } \\
(\mathrm{MWs})\end{array}$ & $\begin{array}{l}\text { Net electricity } \\
\text { generation } \\
(\mathrm{MWe})\end{array}$ & $\begin{array}{l}\text { Net generation vs. } \\
\text { B-100 } \\
(\mathrm{MWe})\end{array}$ & $\begin{array}{l}\text { Supplied heating } \\
\text { steam } \\
(\mathrm{MWt})\end{array}$ \\
\hline \multicolumn{6}{|c|}{ Base turbine } \\
\hline B-VWO & 486.5 & $1,054.7$ & $1,518.3$ & N/A & - \\
\hline B-100 & 465.8 & $1,010.8$ & $1,455.3$ & 0 & - \\
\hline B-H725 & 417.6 & 867.1 & $1,265.2$ & -190.1 & $\sim 530$ \\
\hline B-H1450 & 369.1 & 724.2 & $1,075.5$ & -379.8 & $\sim 1,060$ \\
\hline B-L725 & 500.9 & 833.1 & $1,314.0$ & -141.3 & $\sim 550$ \\
\hline B-L1450 & 541.9 & 653.8 & $1,176.9$ & -278.4 & $\sim 1,100$ \\
\hline \multicolumn{6}{|c|}{ Modified turbine } \\
\hline M-VWO & 452.0 & $1,080.4$ & $1,510.6$ & N/A & - \\
\hline M-100 & 432.5 & $1,036.7$ & $1,448.0$ & -7.3 & - \\
\hline M-H725 & 388.2 & 891.4 & $1,260.1$ & -195.2 & $\sim 530$ \\
\hline M-H1450 & 343.5 & 745.8 & $1,071.5$ & -383.8 & $\sim 1,060$ \\
\hline M-L725 & 468.6 & 858.4 & $1,307.1$ & -148.2 & $\sim 550$ \\
\hline M-L1450 & 510.5 & 677.1 & $1,168.9$ & -286.4 & $\sim 1,100$ \\
\hline
\end{tabular}


Table 2 Steam line sizing calculations vs. baseline volume flow.

\begin{tabular}{lllllllllll}
\hline Case & MS & Rht. 2 & Rht. 1 & ES 7 & ES 6 & ES 5 & ES 4 & ES 3 & ES 2 & ES 1 \\
\hline Base T/G & \multicolumn{1}{c}{} & & & & & & & \\
\hline B-VWO & Base & Base & Base & Base & Base & Base & Base & Base & Base & Base \\
B-100 & $\checkmark$ & $\checkmark$ & $112 \%$ & $107 \%$ & $109 \%$ & $115 \%$ & $115 \%$ & $115 \%$ & $116 \%$ & $\checkmark$ \\
B-H725 & $\checkmark$ & $\checkmark$ & $123 \%$ & $116 \%$ & $120 \%$ & $135 \%$ & $135 \%$ & $135 \%$ & $136 \%$ & $106 \%$ \\
B-H1450 & $\checkmark$ & $\checkmark$ & $117 \%$ & $107 \%$ & $135 \%$ & $113 \%$ & $113 \%$ & $115 \%$ & $115 \%$ & $\checkmark$ \\
B-L725 & $\checkmark$ & $\checkmark$ & $136 \%$ & $114 \%$ & $176 \%$ & $132 \%$ & $132 \%$ & $136 \%$ & $137 \%$ & $\checkmark$ \\
\hline Modified T/G & & & & & & & & $\checkmark$ & $\checkmark$ \\
\hline M100 & $\checkmark$ & $\checkmark$ & $\checkmark$ & $\checkmark$ & $\checkmark$ & $\checkmark$ & $\checkmark$ & $\checkmark$ & $\checkmark$ & $\checkmark$ \\
M-H1.6 & $\checkmark$ & $\checkmark$ & $\checkmark$ & $106 \%$ & $\checkmark$ & $\checkmark$ & $\checkmark$ & $\checkmark$ & $\checkmark$ & $\checkmark$ \\
M-H3.2 & $\checkmark$ & $\checkmark$ & $111 \%$ & $115 \%$ & $\checkmark$ & $121 \%$ & $121 \%$ & $120 \%$ & $117 \%$ & $108 \%$ \\
M-L1.6 & $\checkmark$ & $\checkmark$ & $\checkmark$ & $106 \%$ & $\checkmark$ & $\checkmark$ & $\checkmark$ & $\checkmark$ & $\checkmark$ & $\checkmark$ \\
M-L3.2 & $\checkmark$ & $\checkmark$ & $124 \%$ & $114 \%$ & $145 \%$ & $118 \%$ & $118 \%$ & $121 \%$ & $117 \%$ & $\checkmark$ \\
\hline
\end{tabular}

HPT shaft power increases significantly when compared to the base case. The modified turbine shows some improvement on shaft power. However, the challenge is still present and it is advised that the turbine vendor should perform all the required analyses.

Table 2 shows results for steam line sizing analysis, which is necessary to assess suitability of the current design to accommodate the cogeneration operations. It was assumed that the current APR1400 design can accommodate up to a $5 \%$ increase in flow velocity within existing design margins. If the calculated line velocity exceeds $105 \%$ of the baseline case, the line velocity is indicated as a percentage of the baseline case velocity for each line. MS and 2nd stage reheating steam (Rht. 2) are not adversely impacted by cogen operations. Hence, no design changes are required for these systems. However, a significant velocity increase was found for 1st stage reheating steam (Rht. 1) and all ES lines (ES Nos. 1 through 7).

Similar analysis was also performed for control valve sizing for the HD System. Again, valve duty of less than $105 \%$ of the base case requirement was considered to be within normal design margins, and would not require a change to hardware. The analysis indicates adequate margin across all valve positions in the current design for the following cases: (1) B-H725, (2) M100, (3) M-H725, and (4) M-L725. For other cases and valve positions, the increase in required valve capacity is from 8 to $45 \%$.

The CD (condensate) and FW Systems have been analyzed and no adverse impacts were identified. The condensate pumps and feedwater booster and main feedwater pumps remain within the existing design basis for pump flow, NPSH ratio, pump speed, and flow vs. BEP (best efficiency point).

Fig. 2 shows the hot reheat operating pressure with and without cogen export. There is a significant pressure reduction for both baseline and modified turbine cases. For the baseline turbine design, it is unlikely that the existing MFWP turbine design will have adequate capacity to meet design duty using only hot reheat and a redesign is likely to be required. For the modified turbine design, the MFWP turbine design may be adequate for $750 \mathrm{t} / \mathrm{h}$ steam export for HPE and LPE cases. In any case, a new design specification and vendor review will be required.

\section{Design Considerations}

Beyond the most significant impacts of cogen operations identified in Tables 1 and 2 and Fig. 2, a review of system and component design considerations is further outlined in this section. Generally, design for cogen operations would start with design requirements for steam export and condensate return quantities, thermodynamic parameters, and the interface locations with the APR1400 steam cycle. While the analysis supporting this paper did not identify significant design 


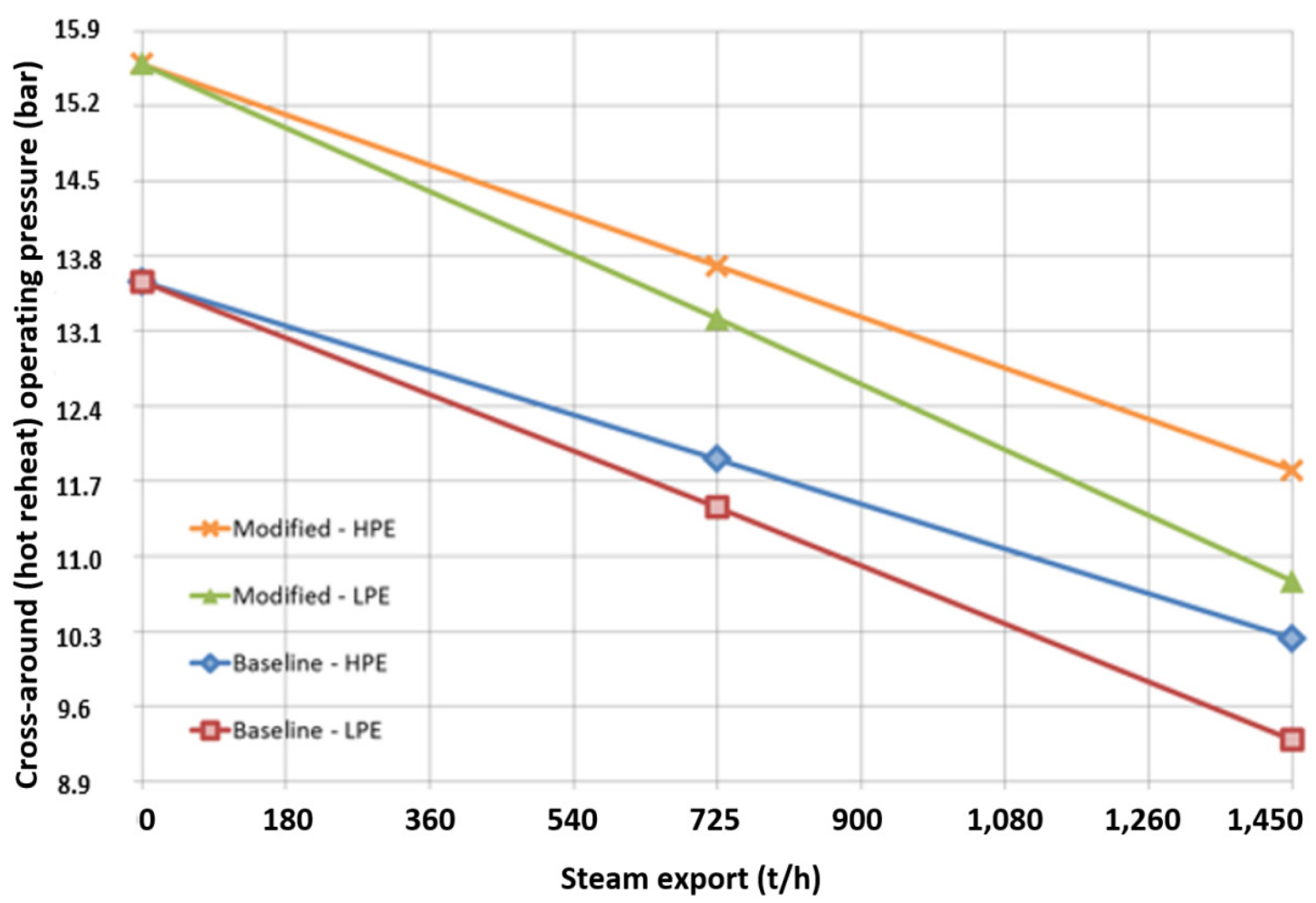

Fig. 2 Hot reheat operating pressure with cogen export steam.

changes beyond those identified above, the review should encompass the scope described below. The design challenges for the steam systems of APR1400 are listed below:

- MS system;

- design pressure and temperature ratings,

- throttle margin revision,

- pipe stress and support load analysis,

- steam hammer loading, and

- containment isolation capability.

- Cross-around steam system;

- cold reheat,

- velocity analysis for LPE cases,

- 1st Stage reheating steam velocity for all design conditions,

- CARV (cross-around relief valve) sizing and press setpoint.

- ES system;

- ES nozzles and line sizing,

- ES expansion bellows (e.g., design to EJMA criteria, stress loading, limiting velocity),
- ES NRVs (non-return valves),

- ES block valves.

As described in Section 4, MS piping is not adversely impacted in the cogen scenario, but it should be noted that some analyses to confirm the design suitability should be performed. Due to bounding thermal, weight, seismic, and fluid transient loading conditions, no changes to the piping, piping supports, or components of the MS system are expected.

Cross-around steam system is significantly affected in LPE cases and the T/G supplier should provide sufficient analyses to address steam pressure and mass flow rate changes. Moreover, CARV sizing should be re-evaluated and the proper pressure setpoint should be established.

The ES System is expected to experience velocity increases in some cases of up to $75 \%$. These changes may impact FAC (flow accelerated corrosion) rates and vibration induced fatigue failures in expansion bellows.

Components which are expected to experience 
challenges related to the cogen applications include: (1) turbine-generator, (2) FWHs, (3) MSRs, (4) MFWP turbine, and (5) main condenser. Operating parameters affecting these components should be analyzed and addressed by experienced designers in order to meet the requirements of the cogen application. The most affected component is the MFWPT. A comprehensive analysis should be conducted to assure good performance. One solution to overcome the MFWP turbine challenge could be replacement of the turbine drive with a medium voltage electrical motor feed by a VSD (variable speed drive). A separate analysis should be conducted for the Main Condenser once the external cogen cycle is decided. Such a review will be important particularly for cycle efficiency calculations, since the return water/steam temperature will determine the injection point back to the system. If the temperature is high enough, the return product can be injected downstream of either FWH No. 1 or FWH No. 2, leading to improved efficiency of the cycle.

Although the interface with the NSSS (nuclear steam supply system) is another important factor to be considered for the cogen application, the NSSS design and operations are expected to see little impact. The only component of the NSSS which is materially affected by the cogen application is the $\mathrm{S} / \mathrm{G}$ (steam generator), due to the fact the final feedwater temperature is reduced. Additional heat transfer in the economizer will be necessary because of the reduced temperature of feedwater entering the $\mathrm{S} / \mathrm{Gs}$.

\section{Conclusions}

Cogeneration has the potential to diversify the revenue stream for NPPs and may represent a viable option for many countries and circumstances. Cogeneration may be a good option to boost industry, provide potable water, or supply district heat for certain regions. These solutions would be the most economical if the heat demand was large (in range from $500 \mathrm{MWt}$ to $1,000 \mathrm{MWt}$ ), ideally year-round. In this study, it was demonstrated that the nuclear steam cycle of the
APR1400 can provide a good foundation for cogeneration applications.

The steam export location considerations have been identified. For either HPE or LPE cogen steam, modifications are recommended. The most significant impacts are associated with the following components: (1) $\mathrm{T} / \mathrm{G}$ shaftline and steam flow path, (2) MFWP drive unit (i.e., steam turbine), (3) HD and MSR drain control valves (sizing), (4) ES System (line and in-line component sizing), (5) FWHs (various design considerations), and (6) MSRs (LPE cases only). These issues should be addressed by system designers and respective component vendors, but it can be assumed that they can economically adapt the current design to the cogen application.

In the course of this study, the need for the further research on detailed design of the steam export system and its interface with the tertiary system. Such research will provide sufficient data for refined efficiency considerations.

\section{Acknowledgments}

This research was supported by the 2016 research funds of the KEPCO International Nuclear Graduate School (KINGS) and the IAEA (International Atomic Energy Agency).

\section{References}

[1] Jacobs, J. A., and Schneider, M. 2009. Cogeneration Application Considerations. GER-3430G, GE Energy.

[2] Losev, V. L., Sigal, M. V., and Soldatov, G. E. 1989. "Nuclear District Heating in CMEA Countries." International Atomic Energy Agency Bulletin 31 (3): 46-9.

[3] IAEA. 2008. Advanced Applications of Water Cooled Nuclear Power Plants. IAEA-TECDOC-1584.

[4] Bergoth, N. 2008. Large-Scale Combined Heat and Power (CHP) Generation at Loviisa Nuclear Power Plant Unit 3. Finland: HighTech.

[5] United States Atomic Energy Commission, Division of Technical Information. 1970. Nuclear Reactors Built, Being Built, or Planned in the United States. TID-8200 (22nd Rev.).

[6] Abdoelatef, M. G., Field, R. M., and Lee, Y. K. 2016. "Economic Evaluation of Coupling APR1400 with a 
Desalination Plant in Saudi Arabia." Journal of the Korea Society of Systems Engineering 12 (1): 73-87.

[7] Abdoelatef, M. G., Field, R. M., and Lee, Y. K. 2015. "Thermodynamic Evaluation of Coupling APR1400 with a Thermal Desalination Plant." International Journal of
Chemical, Molecular, Nuclear, Materials and Metallurgical Engineering 9 (11): 1217-25.

[8] Korea Electric Power Corporation, Korea Hydro and Nuclear Power. 2014. APR1400 Design Control Document, Tier 2. U.S. Nuclear Regulatory Commission. 